\title{
Genetic relationships of Aeromonas strains inferred from 16S rRNA, gyrB and rpoB gene sequences
}

Correspondence

Antonella Demarta

antonella.demarta@ti.ch

\author{
Mara Küpfer, ${ }^{1}$ Peter Kuhnert, ${ }^{2}$ Bożena M. Korczak, ${ }^{2}$ Raffaele Peduzzi ${ }^{1}$ \\ and Antonella Demarta ${ }^{1}$ \\ ${ }^{1}$ Cantonal Institute of Microbiology, Microbial Ecology, $\mathrm{CH}-6500$ Bellinzona, Switzerland \\ ${ }^{2}$ Institute of Veterinary Bacteriology, University of Bern, $\mathrm{CH}-3001$ Bern, Switzerland
}

\begin{abstract}
Genetic relationships among bacterial strains belonging to the genus Aeromonas were inferred from 16S rRNA, gyrB and $r p o B$ gene sequences. Twenty-eight type or collection strains of the recognized species or subspecies and 33 Aeromonas strains isolated from human and animal specimens as well as from environmental samples were included in the study. As reported previously, the 16S rRNA gene sequence is highly conserved within the genus Aeromonas, having only limited resolution for this very tight group of species. Analysis of a $1.1 \mathrm{~kb}$ gyr $B$ sequence confirmed that this gene has high resolving power, with maximal interspecies divergence of $15 \cdot 2 \%$. Similar results were obtained by sequencing only 517 bp of the $r p o B$ gene, which showed maximal interspecies divergence of $13 \%$. The topologies of the gyr $B$ - and $r p o B$-derived trees were similar. The results confirm the close relationship of species within the genus Aeromonas and show that a phylogenetic approach including several genes is suitable for improving the complicated taxonomy of the genus.
\end{abstract}

\section{INTRODUCTION}

Bacteria belonging to the genus Aeromonas (family Aeromonadaceae) are widespread in the environment, especially freshwater, and have been implicated as pathogens in human and animal diseases (Joseph \& Carnahan, 2000; Crivelli et al., 2001). The taxonomy of the genus is complex and has been submitted to ongoing change due to newly described species (Pidiyar et al., 2002; Harf-Monteil et al., 2004; Miñana-Galbis et al., 2004) as well as reclassification and emended or extended descriptions of existing taxa (Pavan et al., 2000; Huys et al., 2002, 2003, 2005; Esteve et al., 2003; Demarta et al., 2004b). At present, the genus Aeromonas comprises at least 18 species validated on the basis of DNA-DNA hybridizations (Martin-Carnahan \& Joseph, 2005).

Phylogenetic analysis based on the 16S rRNA gene is considered an appropriate tool for the reconstruction of evolutionary history and phylogenetic relationships of bacterial genera and it is universally used (Woese et al., 1990; Stackebrandt \& Goebel, 1994; Amann et al., 1995). In the case of Aeromonas, 16S rRNA gene sequences indicated that the genus is composed of a very tight group of

Abbreviation: $\mathrm{HG}$, hybridization group.

The GenBank/EMBL/DDBJ accession numbers for the new gyrB and $r p o B$ sequences obtained in this paper are given in Fig. 2. species, some of them differing by only a few nucleotides (Martinez-Murcia et al., 1992). Moreover, some discrepancies have been observed between $16 \mathrm{~S}$ rRNA gene sequencing and DNA-DNA hybridization results (Sneath, 1993; Martínez-Murcia, 1999) and the existence of 16S rRNA gene polymorphism has been reported recently, particularly in Aeromonas media and Aeromonas veronii strains (Morandi et al., 2005). Other genes have therefore been evaluated as tools for the phylogenetic and taxonomic analysis of this genus.

Housekeeping genes are considered to be better molecular markers than the 16S rRNA gene for the study of phylogenetic and taxonomic relationships at the species level. In several species of bacteria, nucleotide sequence analysis at multiple protein-encoding loci has led to reliable phylogenies that have improved our understanding of population structure as well as epidemiology (Stackebrandt et al., 2002; Urwin \& Maiden, 2003).

Yamamoto \& Harayama (1995) designed a set of primers that allowed both the amplification and the nucleotide sequencing of portions of the gyrB gene (which encodes the B-subunit of DNA gyrase) from various bacteria and demonstrated that phylogenetic analyses of gyrB nucleotide sequences reflected the evolutionary relationships of closely related species (Yamamoto \& Harayama, 1996; Yamamoto et al., 1999). gyrB sequence analysis has already been used 
Table 1. Aeromonas strains used in this study

ATCC, American Type Culture Collection (Manassas, VA, USA); CDC, Centers for Disease Control (Atlanta, GA, USA); CECT, Colección Española de Cultivos Tipo (Valencia, Spain); CIP, Collection bactérienne de l'Institut Pasteur (Paris, France); DSM, Deutsche Sammlung von Mikroorganismen und Zellkulturen (Braunschweig, Germany); IBS, Institute of Bacteriology, Louis Pasteur University (Strasbourg, France); LMG, Culture Collection of the Laboratorium voor Microbiologie Gent (Gent, Belgium); NCIMB, National Collection of Industrial, Food and Marine Bacteria (Aberdeen, UK).

\begin{tabular}{|c|c|}
\hline Strain & Hybridization group/origin \\
\hline \multicolumn{2}{|l|}{ Type or reference strains } \\
\hline A. hydrophila & HG1 \\
\hline \multicolumn{2}{|l|}{ A. hydrophila subsp. hydrophila ATCC $7966^{\mathrm{T}}$} \\
\hline \multicolumn{2}{|l|}{ A. hydrophila subsp. anaerogenes CIP $76.15^{\mathrm{T}}$} \\
\hline \multicolumn{2}{|l|}{ A. hydrophila subsp. dhakensis CIP $107500^{\mathrm{T}}$} \\
\hline \multicolumn{2}{|l|}{ A. hydrophila subsp. ranae CIP $107985^{\mathrm{T}}$} \\
\hline A. bestiarum CDC $9533-76^{\mathrm{T}}$ & HG2 \\
\hline A. salmonicida & HG3 \\
\hline \multicolumn{2}{|l|}{ A. salmonicida subsp. salmonicida ATCC $33658^{\mathrm{T}}$} \\
\hline \multicolumn{2}{|l|}{ A. salmonicida subsp. achromogenes NCIMB $1110^{\mathrm{T}}$} \\
\hline \multicolumn{2}{|l|}{ A. salmonicida subsp. masoucida ATCC $27013^{\mathrm{T}}$} \\
\hline \multicolumn{2}{|l|}{ A. salmonicida subsp. pectinolytica DSM $12609^{\mathrm{T}}$} \\
\hline \multicolumn{2}{|l|}{ A. salmonicida subsp. smithia NCIMB $13210^{\mathrm{T}}$} \\
\hline A. caviae ATCC $15468^{\mathrm{T}}$ & HG4 \\
\hline \multicolumn{2}{|l|}{ A. media } \\
\hline A. media CDC $0862-83$ & HG5A \\
\hline A. media ATCC $33907^{\mathrm{T}}$ & HG5B \\
\hline A. eucrenophila NCIMB $74^{\mathrm{T}}$ & HG6 \\
\hline A. sobria CIP $7433^{\mathrm{T}}$ & HG7 \\
\hline A. veronii biogroup Sobria & HG8 \\
\hline \multicolumn{2}{|l|}{ CDC 0437-84 } \\
\hline \multicolumn{2}{|l|}{ ATCC 51106} \\
\hline A. jandaei ATCC $49568^{\mathrm{T}}$ & HG9 \\
\hline A. veronii biogroup Veronii ATCC $35624^{\mathrm{T}}$ & HG10 \\
\hline Aeromonas sp. ATCC 35941 & HG11 \\
\hline A. schubertii ATCC $43700^{\mathrm{T}}$ & HG12 \\
\hline Aeromonas sp. group 501 & HG13 \\
\hline \multicolumn{2}{|l|}{ LMG 17321} \\
\hline \multicolumn{2}{|l|}{ CECT 4254} \\
\hline A. trota ATCC $49657^{\mathrm{T}}$ & HG14 \\
\hline A. allosaccharophila CECT $4199^{\mathrm{T}}$ & HG15 \\
\hline A. encheleia DSM $11577^{\mathrm{T}}$ & HG16 \\
\hline A. popoffii LMG $17541^{\mathrm{T}}$ & HG17 \\
\hline A. culicicola CIP $107763^{\mathrm{T}}$ & - \\
\hline A. molluscorum LMG $22214^{\mathrm{T}}$ & - \\
\hline \multicolumn{2}{|l|}{ A. simiae } \\
\hline CIP $107798^{\mathrm{T}}$ & - \\
\hline IBS S6874 ${ }^{\mathrm{T}}$ & - \\
\hline \multicolumn{2}{|l|}{ Field strains } \\
\hline F458 & Stool of symptomatic child \\
\hline F589, F474 & Stools of patients \\
\hline F674P & Stool of asymptomatic person \\
\hline $\begin{array}{l}\text { F530D, F666I, F713E, F729F, F544A, F553E, F600C, F533E, } \\
\text { F548B }\end{array}$ & Tap water \\
\hline F507C & Pipe swab \\
\hline F567A & Surface swab \\
\hline V1, V32, V39, V47, V6, V183 & Droppings from healthy goats \\
\hline
\end{tabular}


Table 1. cont.

\begin{tabular}{|ll|}
\hline Strain & \multicolumn{1}{c|}{ Hybridization group/origin } \\
\hline V83 & Droppings from a healthy tortoise \\
V155 & Droppings from a healthy hen \\
V69, V23 & Droppings from healthy pigs \\
V130 & Droppings from an ill pig \\
V15 & Droppings from a healthy horse \\
V30 & Droppings from an ill horse \\
V97, V168 & Droppings from an ill calf \\
JF2638, JF2689 & Koi \\
JF2853 & Human wound \\
\hline
\end{tabular}

to clarify interspecies phylogenetic relationships within Aeromonas (Yáñez et al., 2003; Soler et al., 2004) and to characterize novel species (Pidiyar et al., 2003).

DNA-dependent RNA polymerase is a multisubunit enzyme that consists of two $\alpha$ subunits (encoded by the $r p o A$ gene), one $\beta$ subunit $(r p o B)$ and one $\beta^{\prime}$ subunit $(r p o C)$. Comparison of $r p o B$ sequences has been used as a basis for phylogenetic analyses among some archaea and bacteria (Klenk \& Zillig, 1994; Mollet et al., 1997, Korczak et al., 2004, 2006), but it has never been applied, to our knowledge, to study relationships among Aeromonas strains.

The use of $r p o B$ sequences for phylogenetic and taxonomic studies of Aeromonas strains was therefore evaluated in comparison to gyrB using the $16 \mathrm{~S}$ rRNA gene as a reference. The sequences obtained from these genes were used to characterize 33 Aeromonas strains isolated from human and animal specimens (carriers or patients) and environmental samples (freshwater, tap water, surface swabs) in order to investigate their taxonomic position and their genetic relatedness within the genus.

\section{METHODS}

Bacterial strains and culture conditions. The Aeromonas strains analysed in this study are listed in Table 1 . The strains were subcultured overnight at $30^{\circ} \mathrm{C}$ under aerobic conditions on Columbia agar base (Oxoid) supplemented with $5 \%$ sheep erythrocytes.

DNA extraction. Genomic DNA was prepared according to a method described previously (Demarta et al., 2000) from cells harvested from blood agar and then resuspended in TE buffer $(10 \mathrm{mM}$ Tris/HCl, $1 \mathrm{mM}$ EDTA, pH 8・0). Alternatively, genomic DNA was prepared using an EZNA Bacterial DNA kit (PeqLab) and finally resuspended in water.

PCR amplification and sequencing. The sets of primers used for amplification and sequencing of $16 \mathrm{~S}$ rRNA, $g y r B$ and $r p o B$ genes are listed in Table 2. Nearly complete $16 \mathrm{~S}$ rRNA gene sequences of the

Table 2. Primers used for $\mathrm{PCR}$ amplification and sequencing of $16 \mathrm{~S}$ rRNA, gyrB and rpoB genes

Primer positions are given according to E. coli numbering. N, Any nucleotide; R, A or G; S, C or G; Y, C or T; M, A or C.

\begin{tabular}{|c|c|c|c|}
\hline Primer & Position & Sequence $\left(5^{\prime} \rightarrow 3^{\prime}\right)$ & Reference \\
\hline \multicolumn{4}{|l|}{ 16S rRNA } \\
\hline $26 f$ & $8-26$ & AGAGTTTGATCATGGCTCA & Demarta et al. (1999) \\
\hline $308 \mathrm{f}$ & 289-308 & GCTGGTCTGAGAGGATGATC & Demarta et al. (1999) \\
\hline $556 \mathrm{r}$ & $575-556$ & CTTTACGCCCAGTAATTCCG & Demarta et al. (1999) \\
\hline \multicolumn{4}{|l|}{ gyrB } \\
\hline $\mathrm{UP}-2 \mathrm{r}$ & $1527-1485$ & AGCAGGGTACGGATGTGCGAGCCRTCNACRTCNGCRTCNGTCAT & Yamamoto \& Harayama (1995) \\
\hline UP-1S & & GAAGTCATCATGACCGTTCTGCA & Yamamoto \& Harayama (1995) \\
\hline $\mathrm{UP}-2 \mathrm{Sr}$ & & AGCAGGGTACGGATGTGCGAGCC & Yamamoto \& Harayama (1995) \\
\hline UP3 & $548-567$ & ACTACGAGATCCTGGCCAAG & This paper \\
\hline UP4 & $997-1014$ & TCCTCCCAGACCAAGGAC & This paper \\
\hline UP5r & $917-897$ & GCCTTCTTGCTGTAGTCCTCT & This paper \\
\hline Rpob-R & 2059-2041 & GTTGCATGTTNGNACCCAT & Korczak et al. (2004) \\
\hline
\end{tabular}


strains were determined by PCR-based DNA sequencing following a protocol described previously (Demarta et al., 1999). Amplification of $\operatorname{gyrB}$ was performed as described by Yamamoto \& Harayama (1995) using primers UP-1 and UP-2r. Primers UP-1S, UP-2Sr as well as newly designed ones (Table 2) were used to obtain $\operatorname{gyr} B$ sequences of approximately $1100 \mathrm{bp}$ according to a method described previously (Demarta et al., 2004a). A fragment of about $560 \mathrm{bp}$ from the $r p o B$ gene was amplified and sequenced as reported by Korczak et al. (2004). The accession numbers of $16 \mathrm{~S}$ rRNA, gyrB and $r p o B$ gene sequences are given on the trees.

Phylogenetic analyses. Nucleotide sequences of $16 \mathrm{~S}$ rRNA, gyrB and $r p o B$ genes were aligned independently and phylogenetically analysed using MEGA version 3.1 (Kumar et al., 2004). Phylogenetic trees were constructed using the neighbour-joining method with genetic distances computed by employing Kimura's 2-parameter method. A phylogenetic tree was also constructed from combined sequences of $r p o B$ and $g y r B$ genes.

\section{RESULTS AND DISCUSSION}

Isolates of our collection were first identified by $16 \mathrm{~S}$ rRNA gene amplification and sequencing using the primers indicated in Table 2. Analyses of a fragment of approximately $1330 \mathrm{bp}$ (positions 45-1394 in Escherichia coli), comprising the two main hypervariable regions of Aeromonas, allowed the construction of the phylogenetic tree in Fig. 1. The taxonomic identification of isolates F544A, F713E, V30 and V168 could not be properly assessed because their sequences were too divergent from those of known hybridization groups (HGs) or genospecies. Moreover, nine strains shared an identical fragment sequence with Aeromonas salmonicida and Aeromonas bestiarum, species which are hardly differentiated on the basis of 16S rRNA genes (Martinez-Murcia et al., 1992).

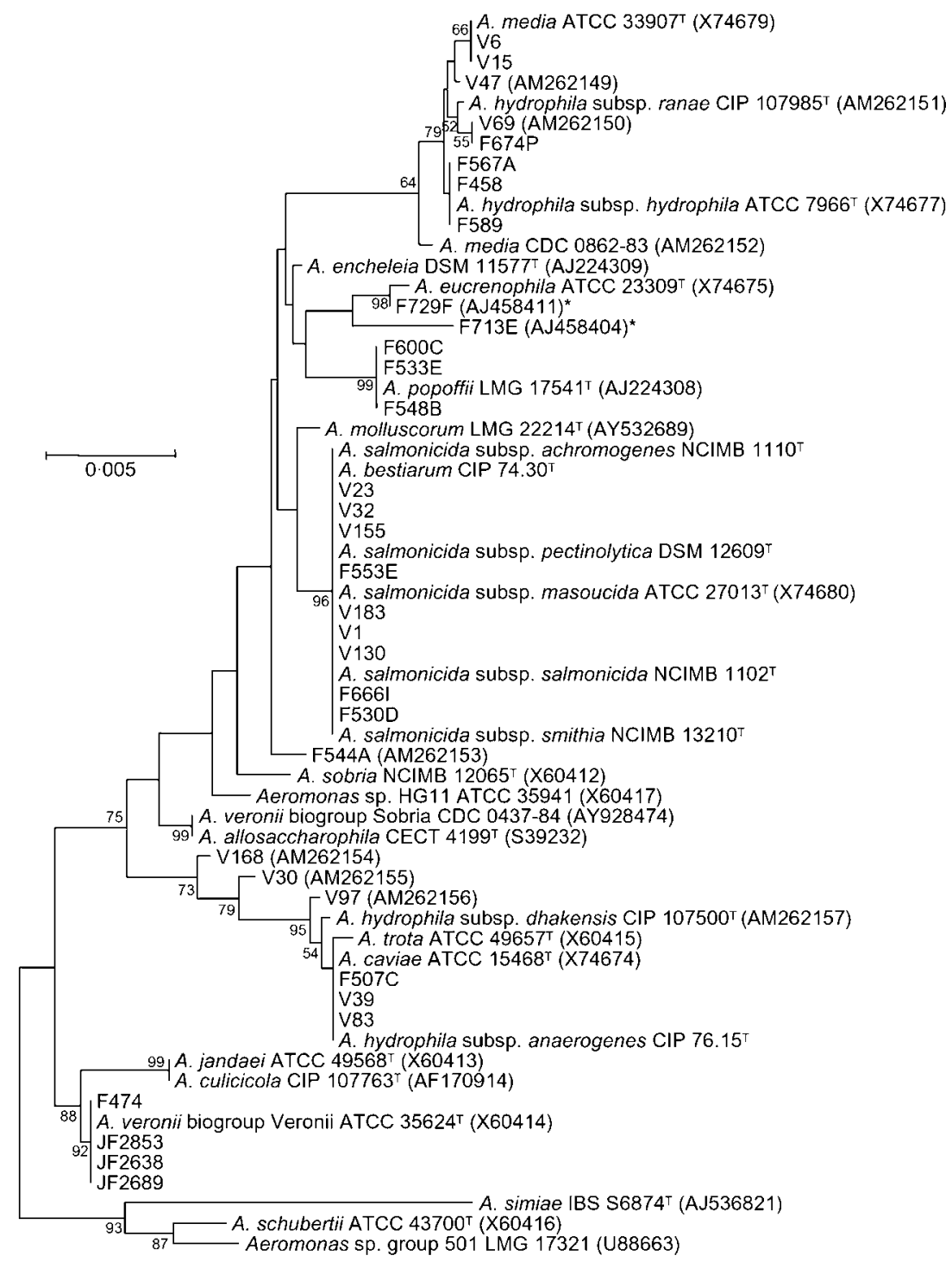

Fig. 1. Unrooted neighbour-joining phylogenetic tree based on a fragment of $1321 \mathrm{bp}$ of the $16 \mathrm{~S}$ rRNA genes of Aeromonas strains. Numbers at nodes indicate bootstrap values (percentages of 1000 replicates). Sequence accession numbers are in parentheses. Strains without accession numbers gave sequences that were found to be identical to another deposited sequence included on the tree; sequences marked by an asterisk were found to be identical to the deposited sequence indicated, although the original source strain is not included on the tree. Bar, 5 changes per 1000 positions 
Using universal primers (Table 2), we could amplify and sequence gyr $B$ fragments of approximately 1100 nucleotides (positions 346-1467 in E. coli K-12). Maximal interspecies divergence of $\operatorname{gyrB}$ sequences was found to be $15 \cdot 2 \%$, whereas the mean divergence was $7 \cdot 76 \%$, values close to those reported by Yáñez et al. (2003).

Primers used to amplify and sequence the $r p o B$ genes of bacteria belonging to the family Pasteurellaceae (Table 2) proved also to be suitable for Aeromonas, allowing the amplification and the sequencing of a 558 nucleotide fragment, which was used to draw the phylogenetic tree in Fig. 2(a). The $r p o B$ region amplified corresponded to codons 500-686 of the 1342 amino acid $\beta$ subunit in E. coli (Ovchinnikov et al., 1981). This segment represents the most variable part of the gene in many bacterial species (Mollet et al., 1997). The maximal interspecies divergence was $13 \%$, with a mean interspecies divergence of $6.07 \%$. $r p o B$ sequences were therefore found to be more conserved than gyrB sequences among Aeromonas strains.

\section{The A. veronii/A. culicicola/A. allosaccharophila group}

Trees derived from $r p o B$ and $g y r B$ sequences grouped these species on the same branch, but the relative positions of single strains differed. In the case of $r p o B$ sequences (Fig. 2a), the reference strains $A$. allosaccharophila CECT $4199^{\mathrm{T}}$ (HG15), A. culicicola CIP $107763^{\mathrm{T}}$ and A. veronii ATCC $35624^{\mathrm{T}}$ (HG10) showed a mean interspecies divergence of $1 \%$. The same low interspecies resolution among these species was reported previously from $r p o D$ sequence analysis (Soler et al., 2004). The rpoB sequences of $A$. culicicola CIP $107763^{\mathrm{T}}$ and A. veronii ATCC $35624^{\mathrm{T}}$ (HG10) were hard to differentiate, presenting a divergence of only $0 \cdot 58 \%$. Recent investigations (Huys et al., 2005) concluded that members of the species A. culicicola in fact belong to the species $A$. veronii. Analysis of $r p o B$ sequences, as well as $g y r B$ and $r p o D$ (Soler et al., 2004), confirmed that A. culicicola could be considered as a synonym of $A$. veronii. Strains JF2638, JF2689, JF2853 and F474 were consequently allocated to the latter species (Fig. 2a). The strain A. veronii biogroup Sobria CDC 0437-84 (HG8) was found to be very similar to A. veronii biogroup Veronii ATCC $35624^{\mathrm{T}}$ (HG10) when $r p o B$ sequences were analysed.

The partial gyrB sequences for this group of species showed an interspecies divergence of about $4 \%$. The mean intraspecies divergence for the subgroup formed by strains JF2638, JF2689, JF2853, F474, A. veronii ATCC $35624^{\mathrm{T}}$ (HG10) and A. culicicola CIP $107763^{\mathrm{T}}$ was $2 \cdot 3 \%$. The partial gyrB sequence of the strain $A$. veronii biogroup Sobria CDC 0437-84 was more closely related to that of A. allosaccharophila CECT $4199^{\mathrm{T}}$ (HG15) than to that of $A$. veronii biogroup Veronii ATCC $35624^{\mathrm{T}}$, as found by Pidiyar et al. (2003), but an almost identical rpoB sequence to A. veronii biogroup Veronii ATCC $35624^{\mathrm{T}}$. This finding therefore represents a case of inconsistency similar to that reported by Yáñez et al. (2003) regarding strain CECT 4911, classified as
A. veronii by Huys et al. (1996) but possessing gyrB and $16 \mathrm{~S}$ rRNA gene sequences similar or identical to those of $A$. allosaccharophila CECT $4199^{\mathrm{T}}$. It should be mentioned that the strain A. veronii biogroup Sobria CDC 0437-84 was found to carry at least two divergent copies of the $16 \mathrm{~S}$ rRNA gene (Morandi et al., 2005)

\section{The A. bestiarum/A. salmonicida/A. popoffii group}

Six strains of animal origin (V1, V130, V183, V32, V155 and V23) as well as three strains isolated from tap water (F666I, F553E and F530D) showed identical 16S rRNA gene sequences to the A. salmonicida and A. bestiarum type strains when the stretch of 1321 bp was considered (Fig. 1). These two species are difficult to separate on this basis because they are reported to differ in only two nucleotide positions over the entire 16S rRNA gene sequence (MartinCarnahan \& Joseph, 2005).

These species could be separated using gyrB (Yáñez et al., 2003; this study) or rpoD (Soler et al., 2004), which showed a resolving power to distinguish $A$. salmonicida from $A$. bestiarum ranging from $6 \cdot 8$ to $8 \cdot 7 \%$. rpoB sequences could also separate these species, although with a lower resolving power (interspecies divergence of $2 \cdot 6 \%$ ). Our collection strains were placed in A. salmonicida genospecies HG3 (strains V1, V130, V183, V32, V155, V23 and F553E) and in A. bestiarum genospecies HG2 (F530D and F666I) by both $r p o B$ and $g y r B$ sequence analysis. Strains belonging to $A$. salmonicida, comprising the subspecies we analysed, formed a very uniform group, with respective intraspecies substitution rates of 1.3 and $0.8 \%$ for $g y r B$ and $r p o B$.

Strains of A. popoffii (LMG $17541^{\mathrm{T}}$, F533E, F548B and F600C) appeared to be closely related to the two abovementioned species by both $r p o B$ and $g y r B$, in agreement with previous reports (Pidiyar et al., 2003; Yáñez et al., 2003) as well as DNA-DNA hybridization results (Huys et al.; 1997b). Probably the best resolution to separate these species can be obtained by using $r p o D$ sequences (Soler $e t$ al., 2004). The finding of perfect matches between the two markers $r p o B$ and gyrB in strains F533E, F548B and F600C suggests that they could be clonally related.

\section{The A. encheleia/Aeromonas sp. HG11/ A. eucrenophila group}

A lasting controversy within the genus Aeromonas is represented by the species A. encheleia HG16 and the unnamed Aeromonas sp. HG11. DNA-DNA relatedness levels reported by Huys et al. (1997a) regarding the strains used in our study clearly allocated Aeromonas sp. HG11 strain ATCC 35941 to the species A. encheleia, despite some atypical reactions in phenotypic tests. As already found for $r p o D$ (Soler et al., 2004), rpoB sequences, showing an interspecies divergence of only $0.78 \%$, did not highlight any phylogenetic divergence between these strains and were therefore congruent with the suggestion that these two taxa 
(a) A. salmonicida subsp. smithia NCIMB $13210^{\top}$ (DQ448286)

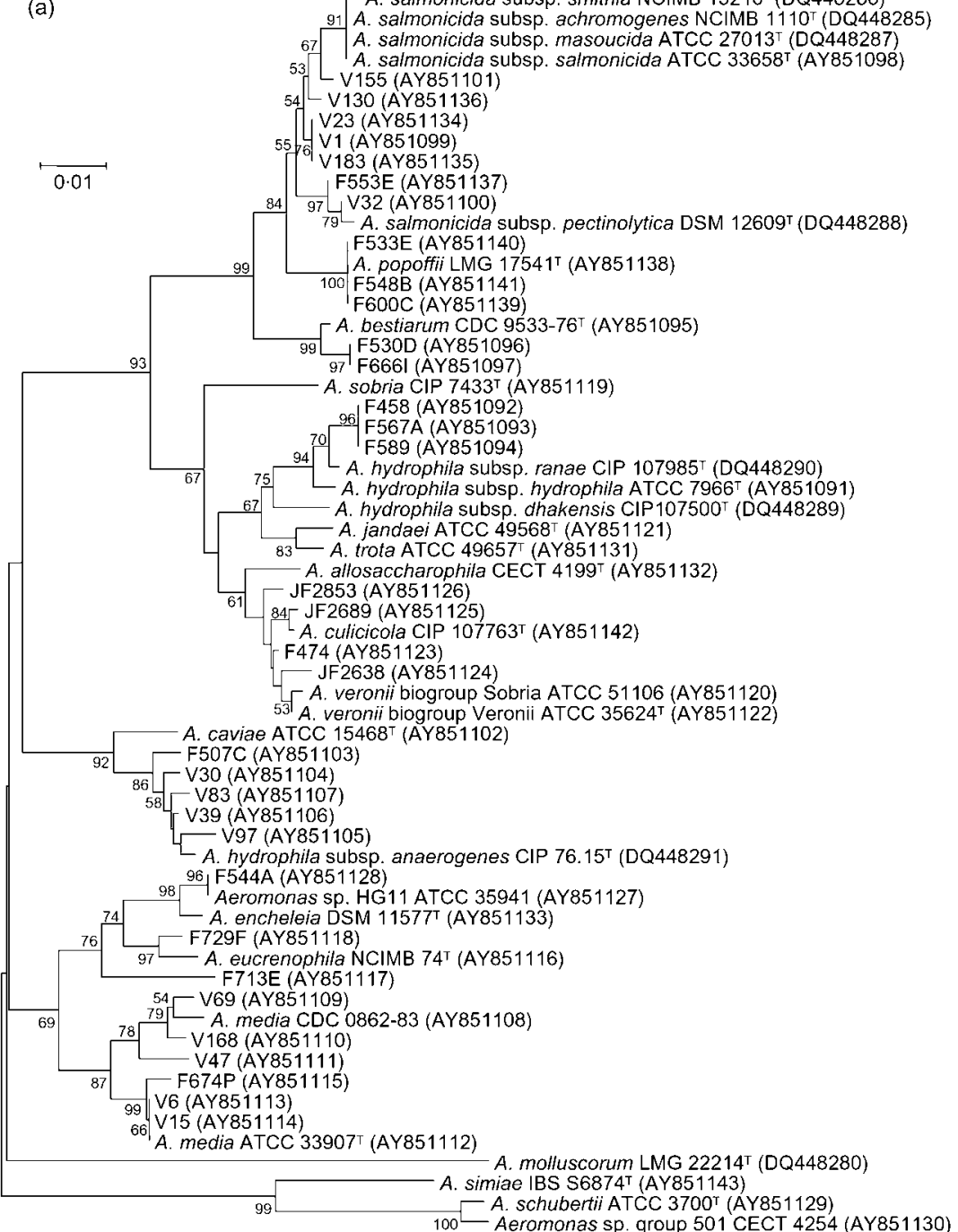

(b) V23 (A.J868368)

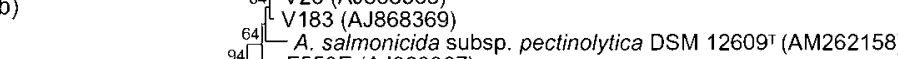
94 C553E (A.J868367) The
F553E (AJ868367)

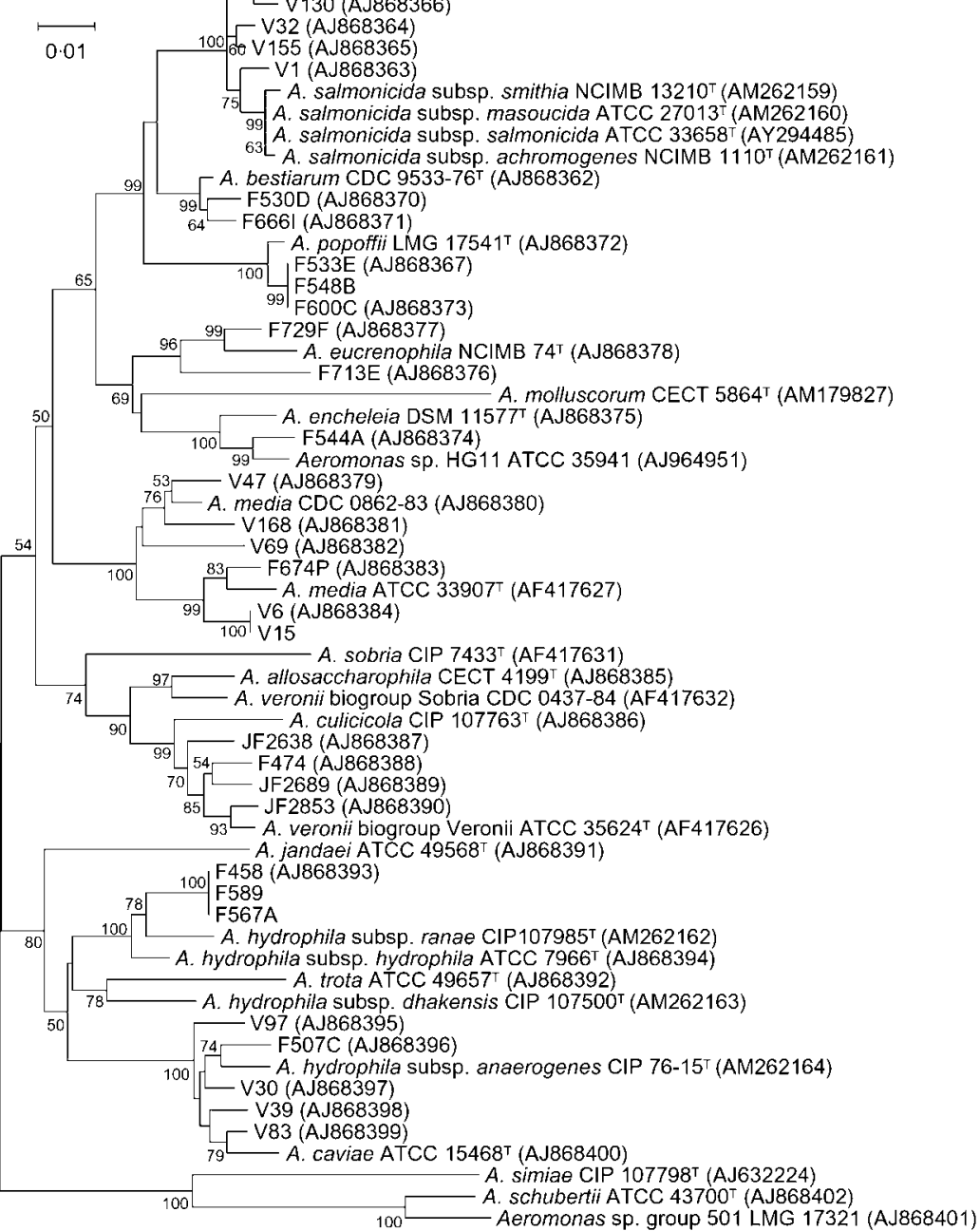

Fig. 2. Unrooted neighbour-joining phylogenetic trees based on $r p o B$ (a) and gyrB (b) gene sequences of $A$ eromonas strains. Numbers at nodes indicate bootstrap values (percentages of 1000 replicates). Sequence accession numbers are in parentheses; strains without accession numbers gave sequences that were found to be identical to another deposited sequence included on the tree. Bars, 1 change per 100 positions. 
should be considered as a single species. The interspecies divergence based on our gyrB sequences was $2 \cdot 3 \%$, in agreement with results reported by Yáñez et al. (2003); this value was also close to the intraspecies nucleotide substitution threshold of $2 \%$ found by Yáñez et al. (2003) for most Aeromonas species. Since only one field isolate (strain F544A) clustered within these strains by both methods, further insight in this group was not possible.

Two strains (F713E and F729F) clustered in the A. eucrenophila branch, but strain F713E showed an $r p o B$ sequence divergence from A. eucrenophila NCIMB $74^{\mathrm{T}}$ of $3 \%(4 \cdot 36 \%$ for $g y r B)$. 16S rRNA gene analysis showed that this strain possessed the same nucleotide sequence as a group of Aeromonas strains described by Demarta et al. (2004b). rpoB and $g y r B$ sequencing results strengthened the hypothesis of the existence of a novel species in the genus Aeromonas, closely related to A. eucrenophila.

\section{The A. media HG5A/A. media HG5B group}

$r p o B, g y r B$ and $16 \mathrm{~S}$ rRNA gene sequences were established for A. media ATCC $33907^{\mathrm{T}}$ (HG5B) and A. media CDC 86283 (HG5A) and for strains V168, V47, V69, F674P, V6 and V15. Apart from strain V168, which clustered with Aeromonas caviae HG4, these strains were grouped in a heterogeneous cluster with Aeromonas hydrophila ATCC $7966^{\mathrm{T}}$ in the $16 \mathrm{~S}$ rRNA gene tree (Fig. 1). rpoB sequence analysis (Fig. 2a) divided these strains into two related subgroups, diverging by $1.9 \%$. The same topology was found with the $g y r B$ tree (Fig. 2b), with a divergence rate for this marker of $3 \cdot 74 \%$. The gyrB sequences of strains V47, V69, V168 and A. media CDC 0862-83 showed a mean similarity of $97 \cdot 8 \%$ with isolates 57,480 and 610 , strains analysed by Soler et al. (2004) which formed a phylogenetically distinct cluster in their $g y r B$ tree.

These results confirmed previous outcomes on the differentiation of the genospecies A. media HG5 into two distinct lines matching the subgroups $5 \mathrm{~A}$ and $5 \mathrm{~B}$, which might constitute two subspecies (Martin-Carnahan \& Joseph, 2005).

\section{The remaining groups}

The rpoB sequence of A. caviae ATCC $15468^{\mathrm{T}}$ (HG4) clustered with five sequences derived from our environmental strains (four of animal origin and one from a pipe swab), as well as with $A$. hydrophila subsp. anaerogenes CIP $76.15^{\mathrm{T}}$, which is considered to belong to the species $A$. caviae. The mean sequence diversity of this species was calculated to be $1.23 \%$ for $r p o B$ and $1.83 \%$ for $g y r B$.

Strains F458, F589 (isolated from stools of patients) and F567A (isolated from a surface swab) showed identical $16 \mathrm{~S}$ rRNA, $r p o B$ and $g y r B$ gene sequences, classifying them as $A$. hydrophila HG1. The identical genetic profiles in three independent markers showed the possible clonal origin of these strains, which were epidemiologically unrelated. The strain A. hydrophila subsp. dhakensis CIP $107500^{\mathrm{T}}$ was found to be the more divergent, regardless of the gene used to draw the phylogenetic tree, among the strains belonging to the species A. hydrophila. The $16 \mathrm{~S}$ rRNA gene sequence placed this strain close to the type strains of A. caviae and Aeromonas trota.

A. sobria (HG7), Aeromonas jandaei (HG9), Aeromonas schubertii (HG12), Aeromonas sp. group 501 (HG13), A. trota (HG14) and Aeromonas simiae were represented in our trees by their type (or reference) strains only. The $\operatorname{gyrB}$ derived tree for these species (Fig. 2b) did not differ from those obtained by other authors (Pidiyar et al., 2003; Yáñez et al., 2003; Soler et al., 2004). In the rpoB tree, only the relative branching positions were subject to change (Fig. 2a).

Since the resolving power of $g y r B$ and $r p o B$ differed in separating some species, a tree (not shown) was derived using the combined sequences joined end to end ( $\sim 1600$ nucleotides). Overall, the combined tree confirmed the positions of species and strains already found in the individual trees. Its reliability in differentiating closely related taxa was improved, as attested by bootstrap values greater than those obtained in single gene analysis.

The majority of the strains isolated from tap water were identified as A. bestiarum or A. popoffii or they were found to belong to the group A. eucrenophila/ A. encheleial Aeromonas sp. HG11. No further distribution of the strains in the phylogenetic tree was noticed related to their origin. Strains isolated from animal droppings were scattered among different genospecies, regardless of the kind of the animal or its health status. It is therefore conceivable that the pathogenic potential of aeromonads is related both to certain host determinants and to strain properties such as the presence of virulence factors.

In conclusion, the use of $r p o B$ and $g y r B$ allowed us to clarify the taxonomy and the phylogenetic relationships of Aeromonas strains isolated from humans, animals and the environment. 16S rRNA gene sequencing was useful to define isolates at the genus level only. In contrast, $g y r B$ sequences were a powerful tool in differentiating Aeromonas genospecies, confirming previous work on Aeromonas (Yáñez et al., 2003; Soler et al., 2004) and similar findings in other bacterial genera (Fukushima et al., 2002; Radice et al., 2006). Moreover, due to the sequence diversity that we could observe in our strains at the intraspecies level, we can agree completely with the suggestion of using $\operatorname{gyr} B$ sequences not only for the identification of species in a phylogenetic framework but also for strain differentiation, as proposed by Yáñez et al. (2003). Although rpoB sequences are more conserved than gyrB sequences in the genus Aeromonas, the present work demonstrated that the resolution of $r p o B$ was sufficient to infer phylogenetic relationships and taxonomic identifications within Aeromonas. Moreover, a similar reliability to $\operatorname{gyr} B$ for differentiating related Aeromonas species could be obtained from analysis of an $r p o B$ fragment of only $560 \mathrm{bp}$. In fact, 
these sequences allowed differentiation between $A$. salmonicida and $A$. bestiarum, as well as $A$. media HG5A and $A$. media HG5B. Furthermore, strain groupings obtained with $r p o B$ were in agreement with the taxonomic classification of all species and subspecies currently recognized in the genus Aeromonas. Finally, rpoB sequences contributed to a clearer understanding of some still controversial taxa of the genus Aeromonas.

\section{ACKNOWLEDGEMENTS}

We thank A.-P. Caminada for her excellent technical assistance. This work was supported in part by the Swiss innovation promotion agency KTI (grant no. 6041.1 KTS).

\section{REFERENCES}

Amann, R. I., Ludwig, W. \& Schleifer, K. H. (1995). Phylogenetic identification and in situ detection of individual microbial cells without cultivation. Microbiol Rev 59, 143-169.

Crivelli, C., Demarta, A. \& Peduzzi, R. (2001). Intestinal secretory immunoglobulin A (sIgA) response to Aeromonas exoproteins in patients with naturally acquired Aeromonas diarrhea. FEMS Immunol Med Microbiol 30, 31-35.

Demarta, A., Tonolla, M., Caminada, A.-P., Ruggeri, N. \& Peduzzi, R. (1999). Signature region within the $16 \mathrm{~S}$ rRNA sequences of Aeromonas popoffii. FEMS Microbiol Lett 172, 239-246.

Demarta, A., De Respinis, S., Dolina, M. \& Peduzzi, R. (2004a). Molecular typing of Yersinia frederiksenii strains by means of $16 \mathrm{~S}$ rRNA and gyrB genes sequence analyses. FEMS Microbiol Lett 238, 423-428.

Demarta, A., Huys, G., Tonolla, M., Swings, J. \& Peduzzi, R. (2004b). Polyphasic taxonomic study of "Aeromonas eucrenophila-like" isolates from clinical and environmental sources. Syst Appl Microbiol 27, 343-349.

Demarta, A., Tonolla, M., Caminada, A. P., Beretta, M. \& Peduzzi, R. (2000). Epidemiological relationships between Aeromonas strains isolated from symptomatic children and household environments as determined by ribotyping. Eur J Epidemiol 16, 447-453.

Esteve, C., Valera, L., Gutiérrez, C. \& Ventosa, A. (2003). Taxonomic study of sucrose-positive Aeromonas jandaei-like isolates from faeces, water and eels: emendation of A. jandaei Carnahan et al. 1992. Int J Syst Evol Microbiol 53, 1411-1419.

Fukushima, M., Kakinuma, K. \& Kawaguchi, R. (2002). Phylogenetic analysis of Salmonella, Shigella, and Escherichia coli strains on the basis of the gyrB gene sequence. J Clin Microbiol 40, 2779-2785.

Harf-Monteil, C., Le Flèche, A., Riegel, P., Prévost, G., Bermond, D., Grimont, P. A. D. \& Monteil, H. (2004). Aeromonas simiae sp. nov., isolated from monkey faeces. Int J Syst Evol Microbiol 54, 481-485.

Huys, G., Coopman, R., Janssen, P. \& Kersters, K. (1996). Highresolution genotypic analysis of the genus Aeromonas by AFLP fingerprinting. Int J Syst Bacteriol 46, 572-580.

Huys, G., Kämpfer, P., Altwegg, M., Coopman, R., Janssen, P., Gillis, M. \& Kersters, K. (1997a). Inclusion of Aeromonas DNA hybridization group 11 in Aeromonas encheleia and extended descriptions of the species Aeromonas eucrenophila and A. encheleia. Int J Syst Bacteriol 47, 1157-1164.

Huys, G., Kämpfer, P., Altwegg, M. \& 7 other authors (1997b). Aeromonas popoffii sp. nov., a mesophilic bacterium isolated from drinking water production plant reservoirs. Int J Syst Bacteriol 47, 1165-1171.

Huys, G., Kämpfer, P., Albert, M. J., Kühn, I., Denys, R. \& Swings, J. (2002). Aeromonas hydrophila subsp. dhakensis subsp. nov., isolated from children with diarrhoea in Bangladesh, and extended description of Aeromonas hydrophila subsp. hydrophila (Chester 1901) Stanier 1943 (Approved Lists 1980). Int J Syst Evol Microbiol 52, 705-712.

Huys, G., Pearson, M., Kämpfer, P., Denys, R., Cnockaert, M., Inglis, V. \& Swings, J. (2003). Aeromonas hydrophila subsp. ranae subsp. nov., isolated from septicaemic farmed frogs in Thailand. Int J Syst Evol Microbiol 53, 885-891.

Huys, G., Cnockaert, M. \& Swings, J. (2005). Aeromonas culicicola Pidiyar et al. 2002 is a later subjective synonym of Aeromonas veronii Hickman-Brenner et al. 1987. Syst Appl Microbiol 28, 604-609.

Joseph, S. W. \& Carnahan, A. M. (2000). Update on the genus Aeromonas. ASM News 66, 218-223.

Klenk, H.-P. \& Zillig, W. (1994). DNA-dependent RNA polymerase subunit $\mathrm{B}$ as a tool for phylogenetic reconstructions: branching topology of the archeal domain. J Mol Evol 38, 420-432.

Korczak, B., Christensen, H., Emler, S., Frey, J. \& Kuhnert, P. (2004). Phylogeny of the family Pasteurellaceae based on rpoB sequences. Int J Syst Evol Microbiol 54, 1393-1399.

Korczak, B. M., Stieber, R., Emler, S., Burnens, A. P., Frey, J. \& Kuhnert, P. (2006). Genetic relatedness within the genus Campylobacter inferred from $r p o B$ sequences. Int $J$ Syst Evol Microbiol 56, 937-945.

Kumar, S., Tamura, K. \& Nei, M. (2004). MEGA3: integrated software for molecular evolutionary genetics analysis and sequence alignment. Brief Bioinform 5, 150-163.

Martin-Carnahan, A. \& Joseph, S. W. (2005). Genus I. Aeromonas Stanier 1943, 213 ${ }^{\mathrm{AL}}$. In Bergey's Manual of Systematic Bacteriology, 2nd edn, vol. 2, part B, pp. 557-578. Edited by D. J. Brenner, N. R. Krieg, J. T. Staley \& G. M. Garrity. New York: Springer.

Martínez-Murcia, A. J. (1999). Phylogenetic positions of Aeromonas encheleia, Aeromonas popoffi, Aeromonas DNA hybridization group 11 and Aeromonas group 501. Int J Syst Bacteriol 49, 1403-1408.

Martinez-Murcia, A. J., Benlloch, S. \& Collins, M. D. (1992). Phylogenetic interrelationships of members of the genera Aeromonas and Plesiomonas as determined by $16 \mathrm{~S}$ ribosomal DNA sequencing: lack of congruence with results of DNA-DNA hybridization. Int J Syst Bacteriol 42, 412-421.

Miñana-Galbis, D., Farfán, M., Fusté, M. C. \& Lorén, J. G. (2004). Aeromonas molluscorum sp. nov., isolated from bivalve molluscs. Int J Syst Evol Microbiol 54, 2073-2078.

Mollet, C., Drancourt, M. \& Raoult, D. (1997). $r p o B$ sequence analysis as a novel basis for bacterial identification. Mol Microbiol 26, 10051011.

Morandi, A., Zhaxybayeva, O., Gogarten, J. P. \& Gral, J. (2005). Evolutionary and diagnostic implications of intragenomic heterogeneity in the 16S rRNA gene in Aeromonas strains. J Bacteriol 187, 6561-6564.

Ovchinnikov, Y. A., Monastyrskaya, G. S., Gubanov, V. V. \& 9 other authors (1981). The primary structure of Escherichia coli RNA polymerase. Nucleotide sequence of the $r p o B$ gene and amino-acid sequence of the $\beta$-subunit. Eur J Biochem 116, 621-629.

Pavan, M. E., Abbott, S. L., Zorzopulos, J. \& Janda, J. M. (2000). Aeromonas salmonicida subsp. pectinolytica subsp. nov., a new pectinase-positive subspecies isolated from a heavily polluted river. Int J Syst Evol Microbiol 50, 1119-1124.

Pidiyar, V., Kaznowski, A., Badri Narayan, N., Patole, M. \& Shouche, Y. S. (2002). Aeromonas culicicola sp. nov., from the midgut of Culex quinquefasciatus. Int J Syst Evol Microbiol 52, 1723-1728. 
Pidiyar, V. J., Jangid, K., Dayananda, K. M., Kaznowski, A., Gonzalez, J. M., Patole, M. S. \& Shouche, Y. S. (2003). Phylogenetic affiliation of Aeromonas culicicola MTCC $3249^{\mathrm{T}}$ based on gyrB gene sequence and PCR-amplicon sequence analysis of cytolytic enterotoxin gene. Syst Appl Microbiol 26, 197-202.

Radice, F., Orlandi, V., Massa, V., Cavalca, L., Demarta, A., Wood, T. K. \& Barbieri, P. (2006). Genotypic characterization and phylogenetic relations of Pseudomonas sp. (formerly P. stutzeri) OX1. Curr Microbiol 52, 395-399.

Sneath, P. H. A. (1993). Evidence from Aeromonas for genetic crossingover in ribosomal sequences. Int J Syst Bacteriol 43, 626-629.

Soler, L., Yáñez, M. A., Chacon, M. R., Aguilera-Arreola, M. G., Catalán, V., Figueras, M. J. \& Martínez-Murcia, A. J. (2004). Phylogenetic analysis of the genus Aeromonas based on two housekeeping genes. Int J Syst Evol Microbiol 54, 1511-1519.

Stackebrandt, E. \& Goebel, B. (1994). Taxonomic note: a place for DNA-DNA reassociation and $16 \mathrm{~S}$ rRNA sequence analysis in the present species definition in bacteriology. Int J Syst Bacteriol 44, 846-849.

Stackebrandt, E., Frederiksen, W., Garrity, G. M. \& 10 other authors (2002). Report of the ad hoc committee for the re-evaluation of the species definition in bacteriology. Int J Syst Evol Microbiol 52, 1043-1047.
Urwin, R. \& Maiden, M. C. (2003). Multi-locus sequence typing: a tool for global epidemiology. Trends Microbiol 11, 479-487.

Woese, C. R., Kandler, O. \& Wheelis, M. L. (1990). Towards a natural system of organisms: proposal for the domains Archaea, Bacteria, and Eukarya. Proc Natl Acad Sci U S A 87, 4576-4579.

Yamamoto, S. \& Harayama, S. (1995). PCR amplification and direct sequencing of gyrB genes with universal primers and their application to the detection and taxonomic analysis of Pseudomonas putida strains. Appl Environ Microbiol 61, 1104-1109.

Yamamoto, S. \& Harayama, S. (1996). Phylogenetic analysis of Acinetobacter strains based on the nucleotide sequences of gyrB genes and on the amino acid sequences of their products. Int J Syst Bacteriol 46, 506-511.

Yamamoto, S., Bouvet, P. J. M. \& Harayama, S. (1999). Phylogenetic structures of the genus Acinetobacter based on gyrB sequences: comparison with the grouping by DNA-DNA hybridization. Int J Syst Bacteriol 49, 87-95.

Yáñez, M. A., Catalán, V., Apráiz, D., Figueras, M. J. \& MartínezMurcia, A. J. (2003). Phylogenetic analysis of members of the genus Aeromonas based on gyrB gene sequences. Int J Syst Evol Microbiol 53, 875-883. 